\title{
Measuring Social Welfare Gains in Social Assistance Programs: An Application to European Countries
}

\author{
Luis Ayala ${ }^{1}$, Elena Bárcena-Martín ${ }^{2}$
}

\begin{abstract}
This paper aims to provide a framework for a complete assessment of the overall welfare gains resulting from social assistance programs. We make use of a social welfare function that satisfies several properties that must be considered when measuring the protection provided by these programs. We propose measuring the welfare gains that a society derives from these programs by summing up them in a way that is consistent with the standard value judgements in the income inequality literature. We also propose analytical tools that accumulate the welfare gains that, apart from having the advantage of being easy to interpret, allow the ranking of different scenarios and have an associated dominance criterion. To illustrate our approach, we measure the welfare gains caused by social assistance schemes in European countries.
\end{abstract}

JEL: D31, D63, I38

Keywords: social welfare, welfare gains, social assistance, minimum income programs

1 Facultad de Ciencias Jurídicas y Sociales, Universidad Rey Juan Carlos, Paseo de los Artilleros s/n, 28032 Madrid, Spain. Email: luis.ayala@urjc.es

2 Departamento de Estadística y Econometría, Universidad de Málaga, Calle Ejido 6 29071, Málaga, Spain. Email: barcenae@uma.es (for correspondence and/or offprints) 